\title{
Modelo LADIR: Inovação no Ensino de Redes de Computadores
}

\author{
André Luiz F. de Oliveira ${ }^{1}$ \\ ${ }^{1}$ Instituto Federal de Educação, Ciência e Tecnologia do Rio Grande do Norte (IFRN) \\ Rua Prof. Carlos Guedes Alcoforado, S.N., Centro, São Gonçalo do Amarante-RN, \\ CEP: 59290-000 \\ andre.oliveiradifrn.edu.br
}

\begin{abstract}
This work presents a laboratory model for the teaching of atypical computer networks that seeks to break with the paradigms of teaching because it attempts to truly promote the insertion of students and teachers in a real and practical environment and, as a result, it is possible to simulate identical situations to what they will find in the labor market. The arrangement of computers racks, audio and video resources, the active and the passive networks are organized to have a visual impact on the users of the environment and then the teaching of networks becomes increasingly attractive and motivational. Consequently, it is possible to unite the usual abstract world of certain contents and immerse in a practical and real universe.
\end{abstract}

Resumo. Este trabalho apresenta um modelo de laboratório para o ensino de Redes de Computadores atípico que procura quebrar com os paradigmas de ensino. Busca promover, verdadeiramente, a inserção dos alunos e docentes em um ambiente real e prático e, com isso, se possibilita simular situações iguais as que eles encontrarão no mercado de trabalho. A disposição dos computadores, racks, recursos de áudio e vídeo, ativos e passivos de redes são organizados para causar um impacto visual nos usuários do ambiente para que o ensino de redes se torne cada vez mais atrativo e motivacional. Com isso,é possível unir o mundo, muitas vezes, abstrato de determinados conteúdos e imergir em um universo prático e real.

\section{Introdução}

O processo de ensino-aprendizagem de redes de computadores, por muitas vezes, é dito como abstrato e de difícil percepção pelos alunos. Não poderia ser diferente, visto que os professores precisam, em um sistema tradicional de ensino, transmitir conteúdos como, por exemplo, os modelos de referência em camadas, os conceitos sobre comunicação de dados, apresentar as normas de cabeamento estruturado, dentre outras e, tudo isso, utilizando o quadro, alguns ativos/computadores e, quando muito, simulando situação reais, mas em um ambiente virtual.

O modelo LADIR (Laboratório Didático de Redes de Computadores) objetiva quebrar esses paradigmas e inovar o ensino de redes, seja quanto à metodologia, seja quanto ao ambiente de aprendizagem. Isto é dito, pois os alunos têm a disposição um ambiente dividido por ilhas de comunicação, que as denominamos de Java, Madagascar, Galápagos e Tasmânia. Dessa forma, ao entrar no laboratório, o aluno sente-se imergindo em um ambiente especial, onde a ludicidade está presente. Assim, eles já começam a se questionar: "No mundo real, como as pessoas que vivem nessas ilhas podem se 
VI Congresso Brasileiro de Informática na Educação (CBIE 2017)

Anais do XXIII Workshop de Informática na Escola (WIE 2017)

comunicar?". O piso suspenso, com suas placas de vidro, já dá alguma dica a partir do momento em que os alunos observam o cabeamento que interliga os racks de cada uma das ilhas.

Este é um dos elementos que contribuem para tornar o ambiente atrativo e motivador para aprender sobre o universo das redes. Isso, se percebe, independente do público que utilize o laboratório que, atualmente, é composto de Jovens e Adultos, integrantes dos cursos Técnicos de Nível Médio em Informática e o Superior em Redes de Computadores. Além do visual atraente do laboratório, cada uma das ilhas possui recursos (ativos e passivos) igualmente divididos que convergem para um rack central. $\mathrm{Na}$ sua totalidade o LADIR pode comportar até 10 alunos por ilha, isto é, 40 alunos no conjunto das ilhas.

A segurança é um item que preocupa quem trabalha com redes, seja no ensino seja na aprendizagem. Foi nesse sentido que o LADIR foi construído, de forma a poder ter sua rede totalmente isolada do ambiente externo. Cada uma das máquinas possui dois cabos de redes, sinalizados por cores diferentes (azul e vermelho), proporcionando aos alunos a tranquilidade para instalar diversos serviços, hospedados em um servidor de rack dedicado que utiliza o VMware. Assim, estabelecemos que, caso o aluno utilize o cabeamento azul, estará na rede geral do prédio e, consequentemente, com saída para a internet. Se utilizar o vermelho, os dados estarão circulando apenas dentro do laboratório, entre as ilhas, em um ambiente seguro e monitorado, seja através de instrumentos de monitoramento como o Zabbix, seja a partir das câmeras IP's, ou dos telefones VOIP's que estão presentes em cada ilha e acabam, também, por proporcionar uma série de práticas que simulam situações reais, com a utilização de equipamentos reais.

Como pode ser percebido, a partir dessa breve introdução, o LADIR proporciona ao estudante uma vivência prática e real dos cenários que eles encontrarão no mercado de trabalho, seja numa dimensão local, regional ou mundial, visto que eles passam a compreender e vivenciar, a partir de uma abordagem física e lógica, o estudo das redes.

Se olharmos pelo lado do docente, além dos recursos e equipamentos diferenciados, o ambiente proporciona que ele ministre suas aulas de forma que as mudanças necessárias nas topologias lógicas e físicas, no decorrer das aulas, não se tornem uma dificuldade, tendo em vista que os enlaces entre as ilhas, e a convergência para o rack central, proporcionam uma configuração muito mais rápida do que se pretende demonstrar ou implementar.

Portanto, o modelo LADIR não procura enfatizar os equipamentos presentes neste laboratório, até porque máquinas, por mais modernas que sejam, se tornam obsoletas e substituíveis. Dessa forma, se preconiza a criação de um modelo de ensino de redes diferenciado, que une teoria e a possibilidade de realizar diversas práticas em um único ambiente, de forma lúdica, atrativa e motivacional, elevando a absorção do conhecimento e o interesse do aluno de modo mais eficiente.

\section{Referencial Teórico}

Para embasar a criação do Modelo LADIR é possível mencionar duas patentes: a US5974446 e a EP1073028A2. O primeiro invento, de 1996, diz respeito a um sistema de ensino à distância, baseado na Internet, para comunicação entre servidor e clientes, em que os clientes se comunicam entre si ou com o professor utilizando diferentes técnicas de comunicação. Este método permite com que diferentes estações de trabalhos se 
VI Congresso Brasileiro de Informática na Educação (CBIE 2017)

Anais do XXIII Workshop de Informática na Escola (WIE 2017)

comuniquem, independentemente da distância geográfica que as separa, seja uma estação com outra, seja uma estação com o servidor. Isto é, ele se refere à internet ou aos sistemas de comunicações semelhantes que proporcionam facilidades na comunicação, seja em tempo real ou não, em um nível regional, nacional e mundial.

Passado pouco mais de 20 anos, constata-se que houve uma evolução dos sistemas de troca de informação, seja com o crescimento das ferramentas educacionais, nomeadamente quanto a educação à distância, seja com o aparecimento de formas de transmissão de áudio e vídeo, de aplicações de comunicação em tempo real, inclusive em dispositivos móveis e, por fim, com a implementação da "internet das coisas". Porém, apesar do universo de possibilidades que surgiram, não houve a criação de instrumentos que pudessem explicar as abstrações conceituais quanto ao ensino de redes de computadores, isto é, o entendimento de como a informação sai de um local e chega a outro continua obscuro e nada atrativo, sob o ponto de vista do estudante. Por mais que renomados autores como Andrew Tanenbaum (2003), Douglas Comer (2016) ou Behrouz Forouzan (2009) tentem retratar e utilizar metáforas para explicar como os dados trafegam de um local para outro, fica sob a responsabilidade do estudante ter uma imaginação fértil para compreender o que o autor quer dizer. Por exemplo, para demonstrar o funcionamento da arquitetura em camadas é feito uma analogia a uma viagem de avião, para entender o tráfego de dados compara-se a uma rodovia, dentre outros.

Por outro lado, há alguns autores como Kurose et al., (2002) que reconhecem essa dificuldade da existência de recursos reais que possam explicar, de forma prática, o que é tratado nos livros de forma abstrata. De acordo com Jim Kurose et al., os cursos que fornecem exposição a ambientes reais de redes ainda estão, em sua maioria, ausentes nos currículos de graduação (2002, tradução nossa). Essa declaração foi instigante para pensar um laboratório que apresentasse uma proximidade com o mundo real para que, de forma motivante e didática, acabasse com esta lacuna apontada pelos pesquisadores.

Algumas empresas criaram soluções em forma de kit's didáticos (maleta ou bancada) para o ensino de redes, mas ainda sem permitir que o aluno consiga vivenciar isso de forma prática e real. Por exemplo, é possível citar a Bit9 Equipamentos Didáticos (http://www.bit9.com.br/) que é detentora de projetos semelhantes, em se tratando de ensino didático de redes, mas só que em uma dimensão minituriarizada. Isto é, foi observado uma ausência de resultados positivos quanto a laboratórios estruturados e idealizados para esse fim específico no Brasil e fora dele, ou seja, a simplificação e a tradução em prática dos conceitos mais abstratos de redes. Dessa forma, partiu-se desta ideia do kit didático e do sistema de ensino cliente-servidor baseado na internet (patente US5974446) para chegar ao conceito de um laboratório que fosse completamente, em todos os seus detalhes, didático.

Já a segunda patente citada (EP1073028A2) é sobre um laboratório de multimídia. Este invento, assim como o projeto aqui proposto, defende a ideia de que a aprendizagem realizada em grupo é mais eficaz do que quando atribuímos um computador a um único usuário. Esse tipo de ensino também foi encontrado no artigo intitulado Recomendação de Conteúdo em um Ambiente Colaborativo de Aprendizagem Baseada em Projetos (2016) apresentado na última edição do Workshop do Congresso Brasileiro de Informática na Educação. De acordo com o trabalho destes autores "[...] foi proposto um modelo de atividade que colocasse os alunos diante de uma forma de aprender diferente 
das utilizadas habitualmente" (Acosta, Reategui e Behar, 2016, p. 38). Isto é, o compartilhamento de hardware e software tornam-se essencialmente interessante para a utilização de um laboratório que possua recursos de multimídia. Ele combina vários elementos, sejam eles novos ou antigos, em um sistema integrado a partir de conexões e switches localizados em uma central de comutação. Assim, os sinais emitidos pelo computador podem ser distribuídos, por um líder ou pelo grupo, o que aumenta a autonomia dos alunos, a partir de interruptores, para um sistema de áudio distribuído na sala e visualizados em uma tela compartilhada, podendo ser visto e revisto diversas vezes. Esse sistema também pode ser percebido a partir do IPC G09B 5/12, que trata de um aparelho educativo de funcionamento elétrico com apresentação individual de informações para vários postos de estudantes, sendo postos diferentes capazes de apresentarem informações diferentes, simultaneamente.

Porém, o modelo LADIR diferencia-se desta segunda patente pela forma que esses recursos multimídias são distribuídos pela sala, bem como por utilizá-los para aproximar professor-aluno e aluno-aluno. Além disso, o citado modelo busca promover, a partir desses recursos, o ensino de conteúdos mais abstratos e, apesar de não ser o objetivo da criação, também pode ser funcional para aulas de informática básica (Sistemas operacionais, aplicativos de escritório ou de designer).

Assim, a partir da análise das duas patentes, acredita-se que este modelo didático para o ensino de redes de computadores permita o crescimento desse campo de ensino e possibilite avanços significativos nas descobertas e inovações nesta área, visto que, pela primeira vez, torna-se possível unir, verdadeiramente, teoria e prática em um único local, de uma forma instigante. Dessa forma, uma vez o aluno motivado, aumenta-se a chance de ele absorver melhor os conteúdos e, consequentemente, criar soluções inovadoras para problemas do nosso dia a dia.

\section{Metodologia}

O Laboratório Didático de Redes de Computadores começou a ser implantado em novembro de 2012, após a fase de levantamento de requisitos, orçamentos e ajustes de infraestrutura civil do ambiente onde seria montada a sala. A partir de então, os ativos e passivos de redes começaram a chegar e após um período longo de pesquisas e análises, a montagem propriamente dita do laboratório iniciou com a instalação do piso elevado, sendo inaugurado nove meses depois, como pode ser visto na sequência lógica de imagens a seguir (Figura 1 a 6 ).

Isto é, durante esse período, os equipamentos foram postos nos seus devidos lugares, juntamente com os móveis e as soluções de áudio e vídeo. Na sequência, foram lançados os cabos de cobre e fibra óptica para que fosse possível conectar os equipamentos de redes. 
VI Congresso Brasileiro de Informática na Educação (CBIE 2017)

Anais do XXIII Workshop de Informática na Escola (WIE 2017)

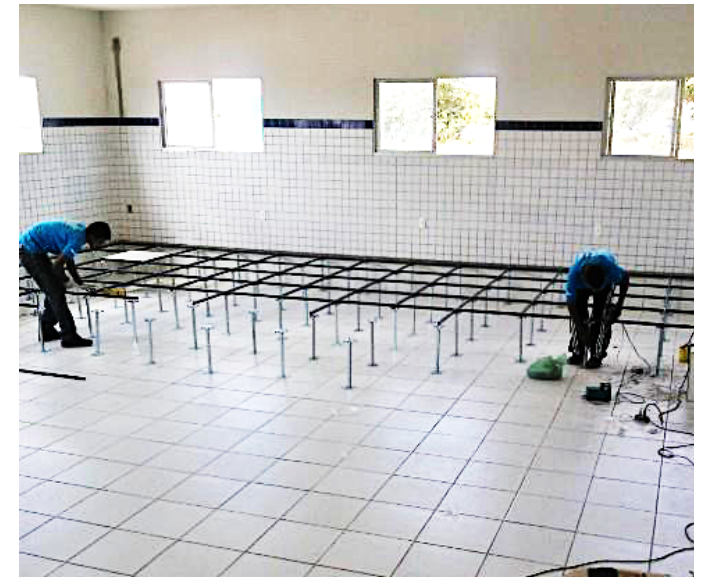

Figura 1 - Montagem do piso elevado

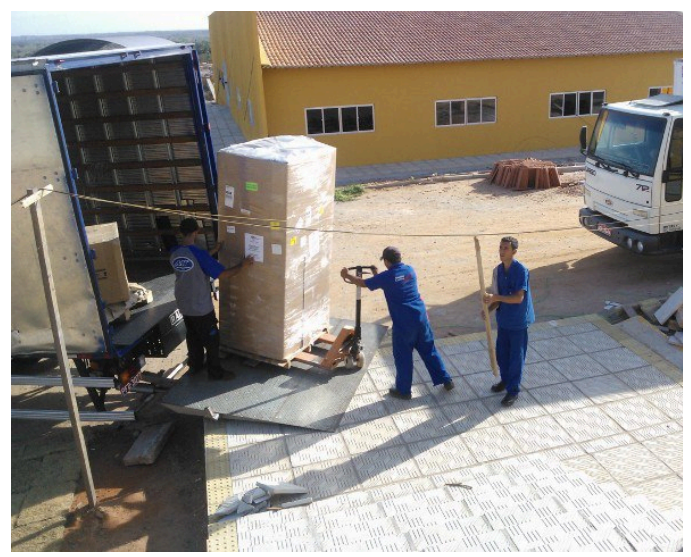

Figura 3 - Chegada dos equipamentos

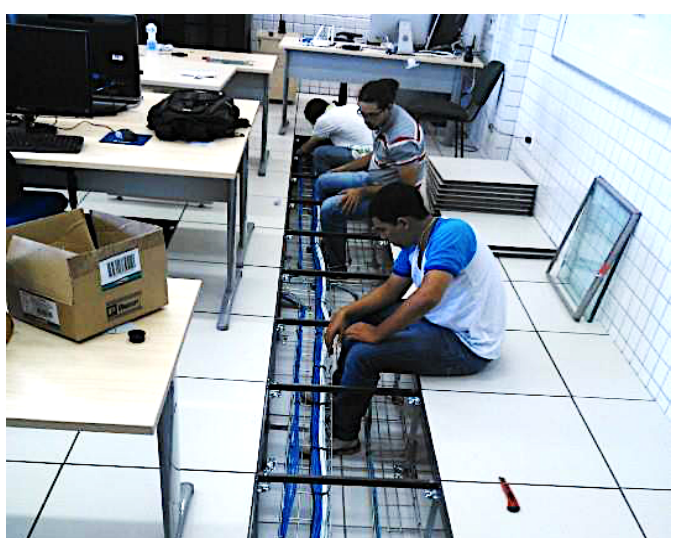

Figura 5 - Organização do cabeamento

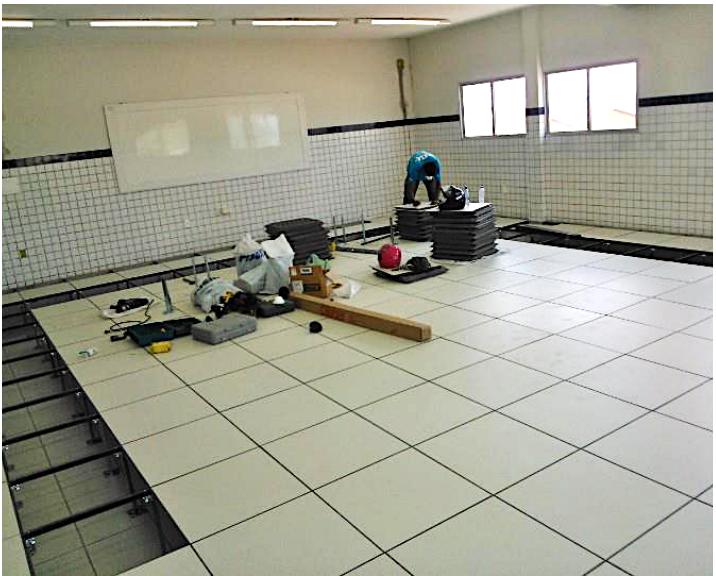

Figura 2 - Montagem do piso elevado

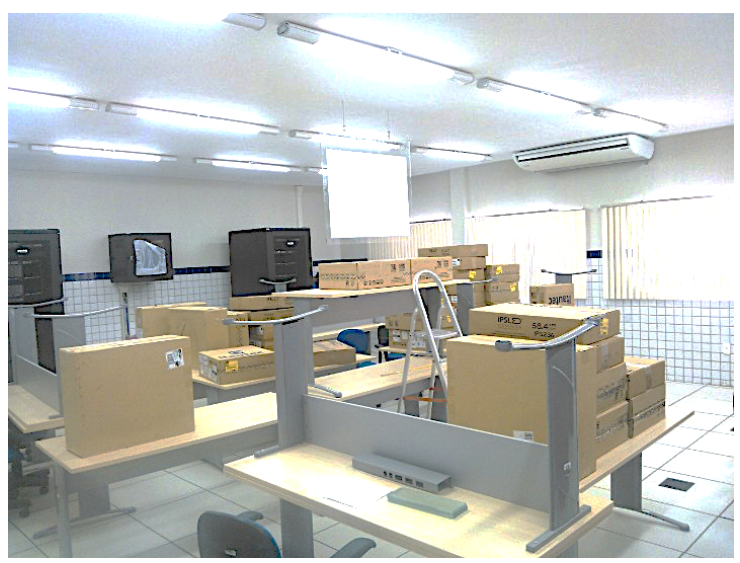

Figura 4 - Organização das mesas

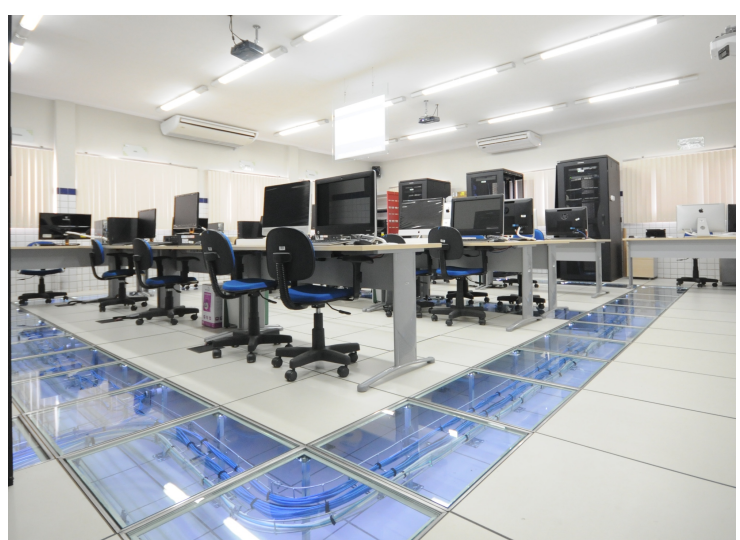

Figura 6 - Resultado final 
VI Congresso Brasileiro de Informática na Educação (CBIE 2017)

Anais do XXIII Workshop de Informática na Escola (WIE 2017)

\subsection{Dificuldades encontradas}

O maior problema encontrado durante esta fase diz respeito ao cumprimento dos prazos, previamente estabelecidos, pela empresa executora do projeto. Mesmo havendo uma supervisão ativa do que estava sendo feito, houve períodos extensos de tempo em que, justificadamente por falta de material, a empresa não se fez presente para dar andamento ao serviço. Além disso, por diversas vezes, encontramos falhas na execução de algumas ações como, por exemplo: na fixação das hastes de sustentação do piso suspenso, na organização do cabeamento horizontal visível ao aluno, na perfuração da passagem de cabos das mesas, etc. Algumas dessas ações puderam ser refeitas, inclusive pelos próprios alunos do curso de Redes de Computadores da Instituição.

\section{Resultados e discussão}

O presente trabalho consiste em uma formulação de laboratório voltado para o ensinoaprendizado, de modo otimizado para estudantes que cursam redes de computadores. $\mathrm{O}$ conceito do laboratório está baseado em proporcionar aos educadores e educandos ferramentas, tanto de audiovisual quanto práticas, que podem apresentar aos usuários do laboratório uma gama de soluções didáticas, de forma a possibilitar a absorção de conteúdos teóricos, inclusive os mais abstratos, de forma dedutiva e experimental e, com isso, aproximar o estudante das práticas encontradas no mercado de trabalho. Para tanto, o laboratório foi idealizado a partir da adoção do conceito de ilhas de comunicação, as quais possuem acesso à instrumentos e recursos que permitem a comunicação entre si e com o mundo.

O projeto possui aspectos inovadores no âmbito do ensino-aprendizagem, em se tratando de práticas laboratoriais e compreensão de conceitos abstratos de redes de computadores. O Laboratório Didático de Redes de Computadores (LADIR), conforme pode ser visto na Figura 8 e 9, compatibiliza vários elementos (televisão (2), projetores interativos (1) e convencionais (3 e 4), sistema de áudio (5) e vídeo integrados $(G)$, tela de projeção (3 e 4), computador, internet, telefone VOIP, câmera IP (6), além dos ativos e passivos das redes), relativamente comuns em laboratórios, mas que aqui deixaram de ser utilizados isoladamente e, agora, foram organizados em um sistema unificado, integrante de um conjunto didático, que aqui chamaremos de modelo LADIR. Através de comutadores e cabeamentos, distribuídos uniformemente pela sala, o conjunto converge para um armário de comunicação central (B), também chamado de rack principal, (composto de servidor, patch painel gerenciável e convencional, switch e distribuidor de fibra óptica) para que, com isso, o docente tenha um maior controle sob as interações e simulações que ocorrem na sala e com o mundo. A organização desta sala foi idealizada para que fosse possível promover uma melhor inserção dos alunos nesse universo e, a partir dai, ajudar na compreensão da rede física e lógica, bem como dos conteúdos abordados.

O termo ilha, aqui utilizado, tem o objetivo de fazer lembrar a localização geográfica, as necessidades e especificidades de uma ilha real, que se apresenta de forma isolada do mundo, mas que, a partir da tecnologia, é possível integrá-la à outras ilhas ou com o continente e, consequentemente, com o resto do mundo. Dessa forma, segmentando o laboratório em ilhas (H, I, J, K e O) é possível o aluno imergir em cada uma dessas realidades e imaginar soluções para os problemas existentes em cada ilha. Utilizando-se ainda da analogia, o discente pode interagir apenas com os "habitantes" da 
VI Congresso Brasileiro de Informática na Educação (CBIE 2017)

Anais do XXIII Workshop de Informática na Escola (WIE 2017)

sua ilha ou, a depender da configuração estabelecida na sala, pode se comunicar com os demais. Esse modelo também permite fazer com que o aluno entenda o que é uma rede e, consequentemente, como se desenvolveu a internet, assim como, a partir de quais elementos e serviços ela é formada. Isto é, se é possível unir dois ou mais computadores que estejam lado a lado, formar uma rede e compartilhar os recursos entre os usuários, também é possível, a partir das tecnologias e instrumentos de conectividade, conectar computadores (pessoas) que não estejam tão próximos.

Ainda no campo do ineditismo, as cinco ilhas de comunicação existentes (quatro destinadas aos alunos (H, I, J e K) e uma para o professor $(\mathrm{O})$ ) são compostas, cada uma, de um armário de comunicação, isto é, rack's secundários (A, B, C, D, E e F sendo todos com 45U, com exceção da ilha do professor (E) que possui 12U), além de possuírem switch, patch painel e distribuidor de fibra óptica, computadores de arquiteturas distintas, telefone VOIP e ter acesso ao servidor central. Com isso, cada líder da ilha, ou um "gerente" designado por ele, pode acessar a máquina virtual atribuída àquela ilha, instalada em um servidor real, existente no rack central (B). Os resultados dessa interação podem ser visualizados por todos, a partir de uma das quatro projeções existentes na sala $(1,2,3$ e 4) e controladas a partir da ilha do professor $(O)$, por meio de um dispositivo centralizador de áudio e vídeo desenvolvido especificamente para este modelo de Laboratório $(\mathrm{G})$. Com isso, se tem a opção de verificar, por exemplo, a partir de gráficos, o desempenho do hardware de cada ilha (processamento, utilização de memória, armazenamento, etc) e, caso seja necessário, fazer um balanceamento dos recursos que se tem disponível e redistribuir entre as ilhas. O dispositivo centralizador de áudio e vídeo (Figura 9) foi criado em virtude do desgaste natural que há nos cabos VGA, tendo em vista que durante um único dia de aula esse cabo é inserido e retirado muitas vezes dos computadores pelos diversos professores que passam pela sala. Assim, para evitar substituições desnecessárias, esses cabos maiores (aproximadamente 12m) foram ligados a adaptadores e estes a cabos VGA's de menor dimensão (aproximadamente $1 \mathrm{~m}$ ). Ou seja, caso eles sejam danificados, troca-se apenas o menor e que se tem fácil acesso ao mesmo, diferente do enlace maior que é proveniente do teto da sala e demanda uma manutenção mais complexa.

A partir do que é projetado e analisado, cada membro do grupo, gerente ou líder pode reagir e tomar decisões, inclusive em grupo ou com auxílio do professor, para melhorar o desempenho da sua ilha, isto é, do seu mundo e, com isso, conseguir compreender o que é preciso fazer para evitar instabilidades ou até mesmo resolver determinados problemas que existem no mundo real das redes de computadores, seja de ordem administrativa, seja de ordem dos softwares ou hardwares. Novamente ratificamos que a ideia aqui demonstrada é totalmente independente dos elementos (hardware/software) que estão em uso, neste momento, no laboratório e que foram aqui descritos, visto que, com o tempo, todos esses recursos ficarão ultrapassados e precisarão ser substituídos, diferente do conceito didático para ensino de redes que tem a capacidade de resistir com o passar dos anos.

Destacamos que o diferencial deste projeto está no fato do discente e docente poder vivenciar e visualizar práticas de um mundo real em um ambiente totalmente controlado, onde ao mesmo tempo em que provoca curiosidades sobre o universo das redes, os inserem em situações que vão exigir deles algumas tomadas de decisões para resoluções de problemas. A possibilidade de estimular o trabalho em equipe é outro ponto a ser considerado neste projeto. Cada uma das ilhas pode ter seu administrador, mas 
VI Congresso Brasileiro de Informática na Educação (CBIE 2017)

Anais do XXIII Workshop de Informática na Escola (WIE 2017)

também é possível unir duas, três ou as quatro ilhas em uma única e distribuir seus "habitantes" conforme a necessidade.

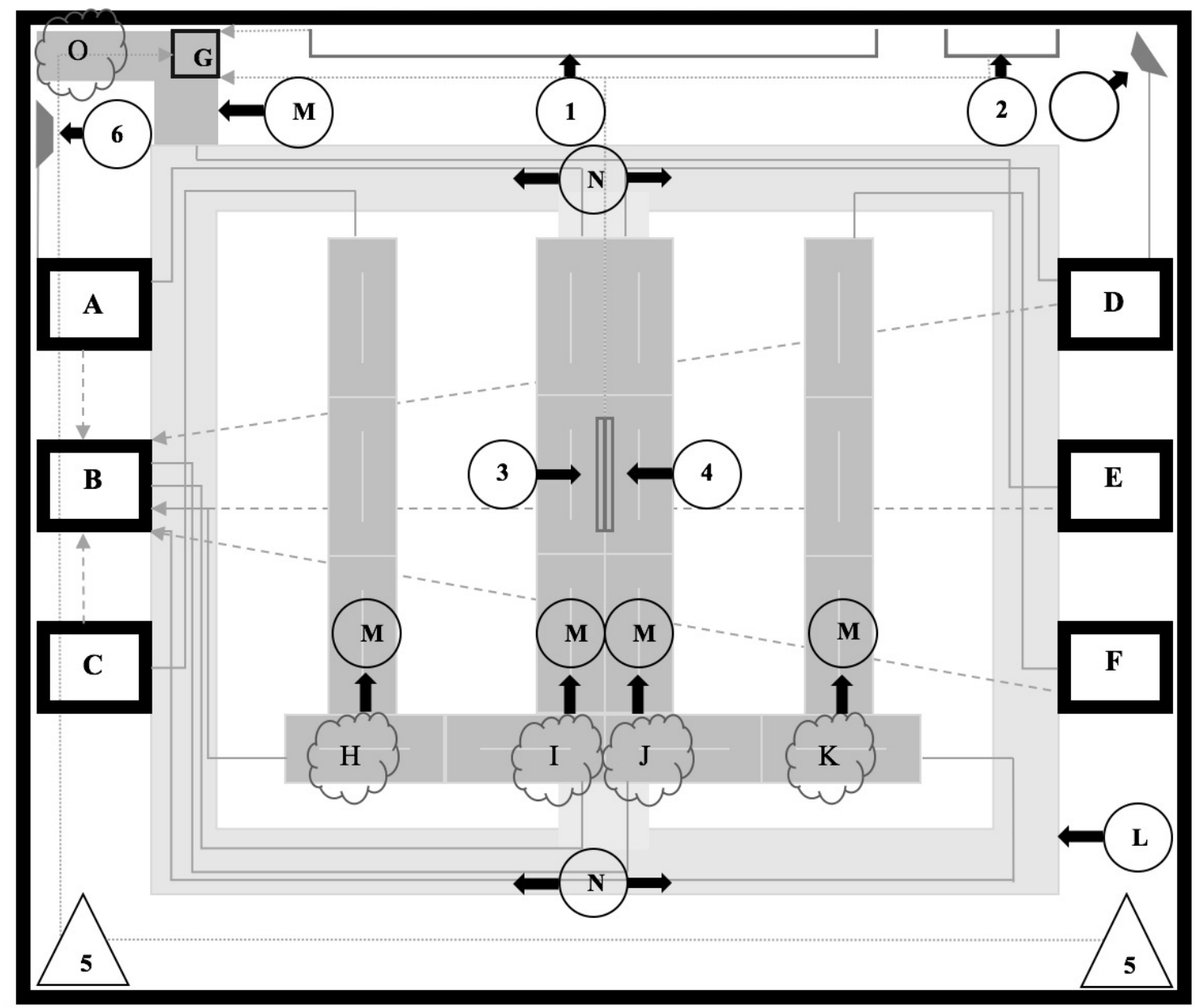

Figura 7 - Planta dos elementos do LADIR

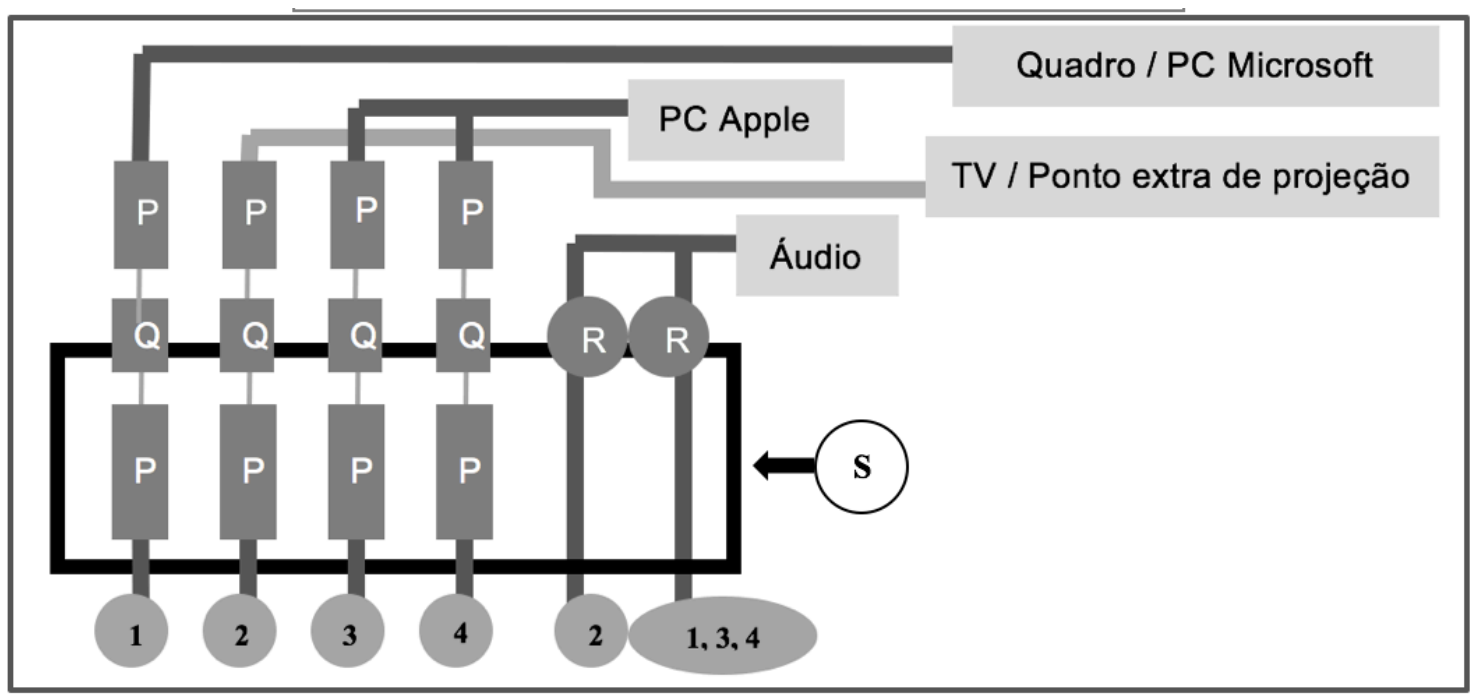

Figura 9 - Dispositivo centralizador de Áudio e Vídeo 
VI Congresso Brasileiro de Informática na Educação (CBIE 2017)

Anais do XXIII Workshop de Informática na Escola (WIE 2017)

\section{Conclusões}

Até o presente momento, os laboratórios para o ensino de redes de computadores tendem a ser tradicionais. Isso significa dizer que os equipamentos são dispostos de maneira isoladas e sem nenhuma unificação entre eles. O resultado disso é uma dificuldade para o professor transmitir o conteúdo para aos alunos, especialmente aqueles mais abstratos que exigem do discente um conhecimento prévio de mundo e uma imaginação criativa. Há algumas tentativas, por meio de softwares, em minimizar esse distanciamento dos alunos, porém o que se consegue, no máximo, com isso, é sair do universo teórico dos livros e entrar em um mundo virtual, onde nem sempre é possível demonstrar algumas práticas que acontecem no dia a dia de um profissional de redes de computadores.

Por isso, reafirmamos que o processo de ensino-aprendizagem de redes de computadores é abstrato e de difícil entendimento por parte dos alunos. Quanto aos professores, estes também enfrentam dificuldades para transmitir o conteúdo, visto que não dispõe de estrutura prática para demonstrar o que os discentes encontrarão no mercado de trabalho.

O Modelo LADIR, a partir de sua organização didática e disposição dos elementos, objetiva acabar com essas dificuldades. Ele é composto por um piso elevado que permite a visualização de todo o cabeamento estruturado a partir das placas de vidros, quatro telas de projeção, equipamentos e instrumentos de conectividade, sistema de áudio e vídeo integrado, um servidor de rack que permite a administração de todas as ilhas e seus usuários, cinco rack's de 45U destinado a interligar as quatro ilhas dos alunos, sendo que um deles, o central, reúne todo o cabeamento dos demais, bem como o da ilha do professor que está ligado a um rack de parede de $12 \mathrm{U}$. Todos os rack possuem um switch, um Distribuir Interno Óptico (DIO) e um patch painel, com exceção do rack central que, além do servidor, possui três switch, sendo um totalmente óptico, dois patch painel angulares tradicionais e dois gerenciáveis, além de um DIO que centraliza a fibra dos demais rack's.

Assim, este laboratório foi desenvolvido em um ambiente totalmente diferente do tradicional, visto que além dos ativos e passivos reais de redes e do piso elevado, também conta com recursos de áudio e vídeo $(1,2,3,4$ e 5), o que proporciona aos alunos e professores uma maior interatividade. O professor controla tudo a partir de sua ilha (O) onde, além de ficar próxima ao rack central (B), possui dois computadores de arquiteturas distintas: um Apple que utiliza o Macintosh e um HP que usa Windows. Cada ilha (H, I, $\mathrm{J}$ e K) também possui as duas arquiteturas, onde o administrador (que são alunos) usa o Macintosh e os demais clientes usam Windows, o que demonstra, de forma imediata, a arquitetura cliente-servidor e a possibilidade de unificação de hardwares distintos, mas que utilizam um mesmo modelo de referência em camadas. Além disso, é possível fazer com que os "habitantes" das ilhas possam trabalhar de forma conjunta ou isolada, seja a partir da manipulação do cabeamento, seja a com a criação de redes virtuais (VLAN`s) na configuração dos Switch's.

Todos esses equipamentos estão funcionando interligados e agora fazem parte de um conjunto unificado didático, voltado para o ensino de redes de computadores, onde o objetivo é fazer uma fusão entre teoria e prática, em que os alunos observam e analisam a teoria posta nos livros e associam a uma realidade composta de atividades práticasintegradas. 
VI Congresso Brasileiro de Informática na Educação (CBIE 2017)

Anais do XXIII Workshop de Informática na Escola (WIE 2017)

\section{Referências}

Acosta, O., Reategui, E. e Behar, P. (2016). "Recomendação de conteúdo em um ambiente colaborativo de aprendizagem baseada em projetos". In: Workshop do Congresso Brasileiro de Informática na Educação - CBIE, Uberlândia, MG. Anais (online). Disponível: http://www.br-ie.org/pub/index.php/wcbie/article/view/6906/4780. Acesso em: 30/05/2017.

Comer, D. E. (2016) "Redes de Computadores e Internet". Bookman Editora, 6 a Edição.

Forouzan, B. A. (2009) "Comunicação de dados e redes de computadores". AMGH Editora, $4^{\text {a }}$ Edição.

Kurose, J. et al (2002). "ACM Workshop de SIGCOMM em Redes de Computadores: Designs Currículo e desafios educacionais". ACM SIGCOMM Computer Communications Review, v. 32, n. 5, n.p.

Tanenbaum, A. (2003). "Redes de computadores". Rio de Janeiro: Editora Campus. 4" Edição. 